\title{
Foraging ecology of sea kraits Laticauda spp. in the Neo-Caledonian Lagoon
}

\author{
François Brischoux ${ }^{1,2, *}$, Xavier Bonnet ${ }^{1}$, Richard Shine ${ }^{3}$ \\ ${ }^{1}$ Centre d'Etudes Biologiques de Chizé - CNRS, 79360 Villiers en Bois, France \\ ${ }^{2}$ Université François Rabelais, 3 rue des Tanneurs, 37041 Tours, Cedex 1, France \\ ${ }^{3}$ Biological Sciences A08, University of Sydney, New South Wales 2006, Australia
}

\begin{abstract}
To understand the magnitude and ecological impact of predation, we need to know not only predator abundance and feeding rates, but also the area from which the prey are taken. Previous work on amphibious sea snakes (sea kraits Laticauda spp.) in New Caledonia has documented the former parameters, and suggested that these marine snakes may be major predators within coralreef ecosystems. To estimate the area over which these snakes forage, we have developed methods based on detailed assessments of (1) the eel species consumed (and, hence, their habitats of origin), (2) the state of digestion (and, hence, time since capture) of prey items inside snakes returning to their home islands after foraging trips, and (3) the rate of digestion of prey in experimental trials. In combination with data on rates of snake movement, we conclude that one species (Laticauda laticaudata) forages mostly on soft-bottom habitats within $23 \mathrm{~km}$ of the home island, whereas the other species (L. saintgironsi) forages on coral substrates within $38 \mathrm{~km}$ of the home island. The distribution of estimated foraging ranges was similar between these 2 species (about one-third of prey taken within a few kilometres of the home island; the rest from a wide range of much further sites), despite interspecific divergence in traits such as prey types, prey sizes and rates of digestion. These extensive foraging ranges suggest that sea kraits are significant predators of eels over the entire area of the lagoon; and imply that populations of these top predators can be affected by disturbance to prey resources even many kilometres from the home island.
\end{abstract}

KEY WORDS: Sea snakes $\cdot$ Diet $\cdot$ Foraging range $\cdot$ Foraging habitat

\section{INTRODUCTION}

In many marine ecosystems, some of the most significant predators are air-breathing animals such as birds and seals, that forage in the ocean but return to land for other activities such as resting and breeding (central place foragers; Elliott 1988). Typically, such animals have a consistent terrestrial home (usually, on an island) to which they return after foraging trips. Studies on the feeding ecology of such predators can clarify not only their trophic effects, but also the distribution and ecology of prey species that otherwise are difficult to monitor (Cherel et al. 2004). Hence, these predators can serve as valuable bioindicators in marine ecosystems (Guinet et al. 2001, Hindell et al. 2003). Measuring the quantities and species composi- tion of prey consumption is relatively straightforward, by observing predators returning to their terrestrial home after foraging trips. However, one critical variable remains difficult to assess: the geographic extent of foraging. Clearly, the impact of predation may be enormously greater if it is concentrated in a small area around the home island, than if predators disperse long distances in their search for prey. Biologists studying seabirds and pinnipeds have utilized small tracking devices to answer this question, but these devices are too large to attach to smaller types of predators. In the present paper we explore the geographic extent of foraging by another type of land-based marine predator that so far has attracted far less scientific attention: sea snakes of the genus Laticauda. 
Unlike the other major lineage of marine snakes (the hydrophiines), laticaudines ('sea kraits') are oviparous animals that forage in the ocean, but return to land to mate, lay their eggs, digest their prey and slough their skins (Heatwole 1999). Although laticaudines are abundant through most of the islands of the IndoPacific (Heatwole 1999), their ecological role in coralreef systems remains unclear. Our detailed markrecapture studies on 2 laticaudine species on a small island in the Neo-Caledonian Lagoon have revealed very high population densities (>1500 snakes on a 6 ha islet), a high degree of philopatry (snakes are rarely recaptured on any island other than the one on which they were first seen) and a high total consumption of prey biomass (>950 kg of anguilliform fish [henceforth 'eels' for simplicity] $\mathrm{yr}^{-1}$ ). The eels on which these snakes prey are difficult to survey by any available technique, and thus the overall abundance of eels in these systems remains unknown (Ineich et al. 2007). The high consumption rates suggest that snakes are significant top predators in this system, but we cannot fully interpret these data without knowing the size of the area over which the snakes collect their prey.

Because direct monitoring of snake movements during foraging bouts is difficult, we are forced to rely on indirect means. The current paper outlines our solution to this problem, based upon measures of (1) the types of eels consumed by each of our 2 laticaudine study species; because such eels are habitat-specific, we can then assess the habitat types from which the snakes obtain their prey; (2) the degree of digestion of prey items inside snakes captured at the end of foraging bouts, as they return to their home island (see Fig. 1); and (3) the rate at which snakes digest their prey (based upon experimental trials), which, in combination with states of digestion (see Point 2 above), allows us to estimate the time interval between a snake capturing an eel and returning to land.

These data can then be combined with existing information on the distribution of habitat types within the Neo-Caledonian Lagoon and on swimming speeds of sea kraits, to estimate the geographic extent of the area over which sea kraits forage for their prey.

\section{MATERIALS AND METHODS}

Study species and general methods. Two species of sea kraits (Elapidae: Hydrophiinae) occur in New Caledonia: the endemic Laticauda saintgironsi (Cogger \& Heatwole 2006) and the widespread L. laticaudata (Saint Girons 1964, Ineich \& Laboute 2002). Both are elongate, brightly banded species, attaining approximately $1.5 \mathrm{~m}$ in maximum length. We surveyed sea krait populations on 9 different islets in the south- west lagoon of New Caledonia (Brischoux \& Bonnet 2007).

Snakes were collected by hand from the islands, measured (snout vent length [SVL], $\pm 1 \mathrm{~cm}$ ), weighed $( \pm 1 \mathrm{~g})$ and individually marked by scale clipping (Brischoux \& Bonnet 2007). The abdomen of each snake was palpated to check for the presence of prey in the stomach. Because the eels consumed by sea kraits are slender and non-spinose, the snakes readily regurgitate their prey if gentle pressure is applied to the rear of the stomach (Brischoux \& Bonnet 2007). We collected, identified, measured and preserved 1077 regurgitated prey items (Böhlke et al. 1999, Smith 1999a,b, Smith \& McCosker 1999, see Brischoux et al. 2007). We quantified niche overlap between the 2 sea krait species with the Morisita-Horn similarity index (Magurran 1988, 2004), using EstimateS 7.5 software (Colwell 2005). To identify the habitats from which eels had been captured, we used FishBase (Froese \& Pauly 2006) to extract information on 29 of the 49 eel species eaten by the sea kraits (habitats of the other taxa are not yet known). For simplicity, we recognised 3 broad types of habitat: hard bottom, soft bottom and coral plus soft bottom.

Elapsed time between prey capture and the snake's return to land. We palpated 309 prey items from snakes that were collected as they returned to the home island ( $<1 \mathrm{~h}$ after arrival), resulting in prey items that ranged from well digested to almost intact. For each prey item, we measured the diameter and the length of the undigested fish or fragment, calculated the state of digestion, and estimated the total initial length of the prey using allometric equations linking body measurements to total length (see Brischoux et al. 2007 for details; Fig. 1).

To quantify rates of digestion, we captured 18 Laticauda laticaudata and 19 L. saintgironsi as they came ashore with a prey item in the stomach, and kept them in captivity in an outdoor arena $(1.2 \times 1.2 \mathrm{~m})$ until digestion was complete. Because the rate of digestion by snakes is sensitive to temperature (Naulleau 1983), we measured snake temperatures in the experimental arena once every $2 \mathrm{~h}$ with an infrared laser thermometer (Raytek MX2). Body temperatures of free-ranging foraging snakes were recorded using surgically implanted temperature loggers (LTD-1110, Lotek Wireless). Thermal regimes for snakes digesting prey in the experimental arena (mean $\pm \mathrm{SD}, 27.6 \pm 1.6^{\circ} \mathrm{C}$ ) were very similar to those of aquatic foragers (26.5 \pm $\left.0.8^{\circ} \mathrm{C}\right)$.

Because the fishes are very large relative to the snakes that eat them and the snake's body wall is very thin compared to the diameter of the fish, it is possible to measure the length and diameter of prey items in a snake's stomach in situ by careful palpation (see Shine 


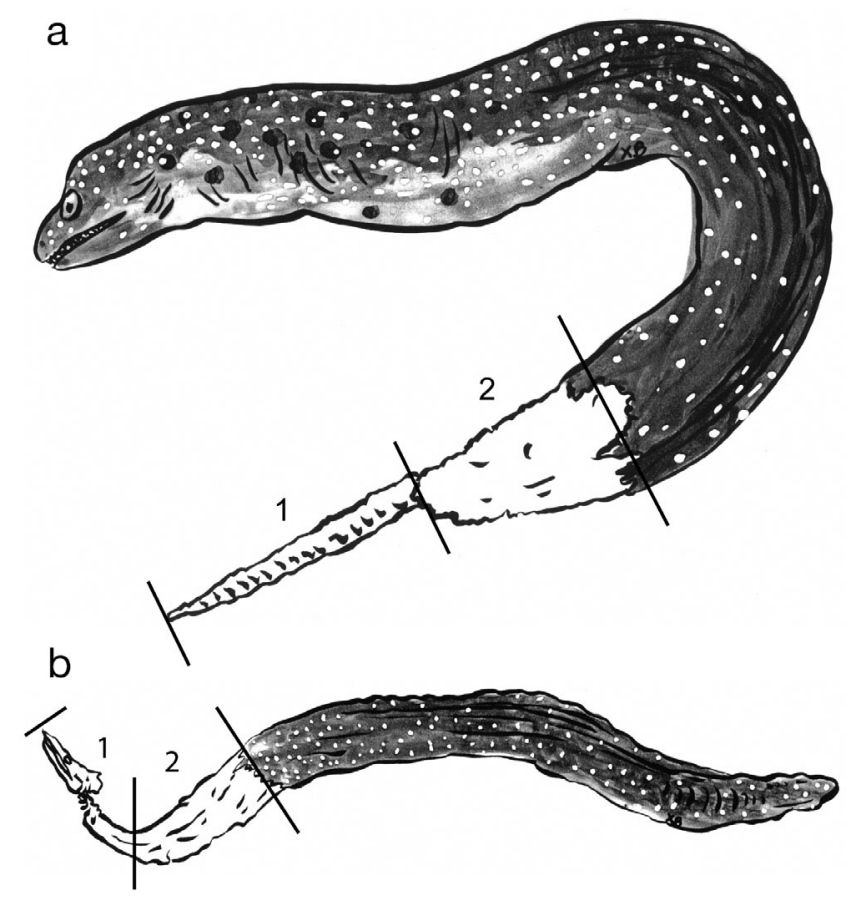

Fig. 1. Gymnothorax eurostus. Specimens of regurgitated moray eels. Note that the extremity first swallowed, (a) tail or (b) head, is progressively digested, while the rest of the prey remains intact. 1: already digested part (only some vertebrae or the skull remain); 2: segment of the prey under digestion when the regurgitation occurred. Drawings (by X. Bonnet) after pictures of freshly regurgitated items, Specimens 121 and 167 deposited in the sea krait prey collection of the Centre d'Etudes Biologiques de Chizé (CEBC-CNRS UPR 1934)

\& Sun 2003 for validation of this method). We measured the length and diameter of the prey every $12 \mathrm{~h}$ until completion of digestion, as indicated by the absence of objects in the abdomen. Using allometric equations linking the length and the diameter of the prey, we estimated initial prey length (Brischoux et al. 2007; mean error $<8 \%$ ), and thus could calculate the rate of digestion. Knowing the state of digestion of prey in snakes returning to their home island after foraging trips (above), we could estimate the duration of time that had elapsed between the capture of prey and the snake's arrival on land.

\section{RESULTS}

\section{Composition of the diet}

We recorded a diverse array of fishes from the alimentary tracts of sea kraits Laticauda spp., comprising 49 species in total. Of these, only 13 were shared by the 2 sea krait species, indicating a clear interspecific dietary divergence (Table 1). Moreover, the shared species were infrequently recorded in at least one of the sea krait species (Table 1). These effects translated into a low value of the Morisita-Horn similarity index: 0.15 (Magurran 1988, 2004). L. saintgironsi fed on a wider prey spectrum than did L. laticaudata (38 versus 24 prey species, respectively; Table 1). However, 1 abundant species (Gymnothorax chilospilus) constituted most of the L. saintgironsi diet $(46 \%$ of prey items; Table 1). In contrast, more than half of the L. laticaudata diet was comprised of 3 eel species (Gymnothorax albimarginatus, Muraenichtys sp., and Conger cinereus; Table 1).

\section{Prey habitat}

Combining these data on prey species with habitatuse information from FishBase (Froese \& Pauly 2006), the 2 sea krait species clearly foraged in different places (Yates $\chi^{2}=591.77, \mathrm{df}=2, \mathrm{p}<0.0001$; Fig. 2). Laticauda saintgironsi fed on prey from hard substrates (mainly within the coral matrix), whereas L. laticaudata fed extensively on eel species from soft-bottom habitats.

\section{Rate of digestion of the prey}

All of the anguilliform prey items that we examined were partially digested from either the anterior or posterior end of the body, but remained intact at the other extremity (Fig. 1). Hence, the rate of digestion can be quantified on a linear axis, corresponding to the pro-

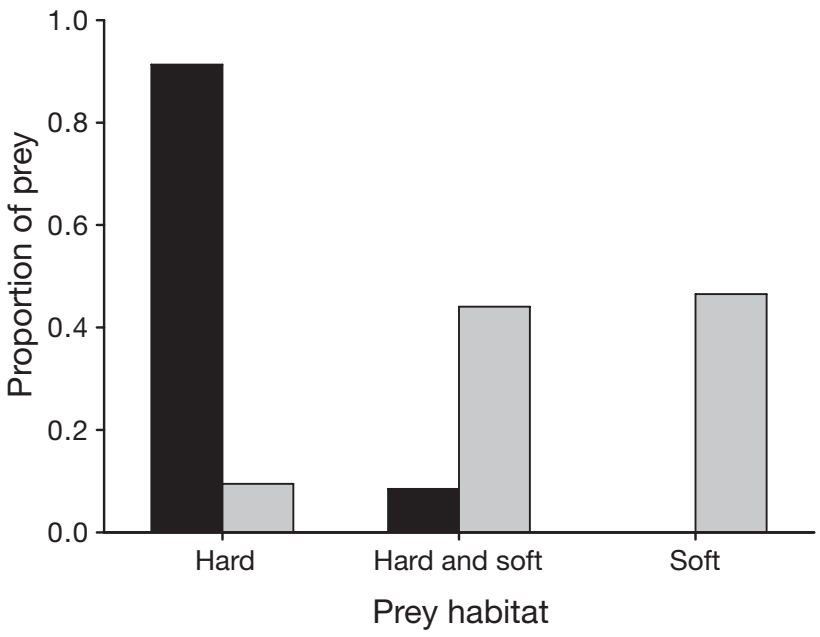

Fig. 2. Laticauda spp. Proportion of sea krait prey taken from 3 types of habitat. Black bars and grey bars show data for $L$. saintgironsi and L. laticaudata, respectively. Due to unknown habitats of several prey species (see 'Materials and methods') and to unidentified prey items, sample sizes were $N=590$ and $\mathrm{N}=286$ for $L$. laticaudata and $L$. saintgironsi, respectively 
Table 1. List of the fish species identified from sea krait Laticauda spp. stomach contents, with their percentage in each diet (L. laticaudata and L. saintgironsi, LL and LS, respectively). Sample sizes were $N=365$ prey items for L. laticaudata and $\mathrm{N}=655$ for $L$. saintgironsi. Habitats were extracted from FishBase (Froese \& Pauly 2006). Species in bold comprise $>10 \%$ of the sea krait diets

\begin{tabular}{|c|c|c|c|}
\hline Prey species & $\begin{array}{l}\text { Percent of } \\
\text { diet of LL }\end{array}$ & $\begin{array}{l}\text { Percent of } \\
\text { diet of LS }\end{array}$ & Habitat \\
\hline Anarchias allardicei & 0.5 & 0.4 & \\
\hline A. cantonensis & 0 & 1.8 & \\
\hline A. seychellensis & 0 & 0.4 & Hard \\
\hline Anarchias sp. & 0 & 0.3 & \\
\hline Cirrimaxilla formosa & 2.7 & 0.7 & \\
\hline Conger cinereus & 23.2 & 3.2 & Hard/Soft \\
\hline Echidna sp. & 0 & 0.3 & \\
\hline E. unicolor & 0 & 0.4 & \\
\hline Enchelycore pardalis & 0 & 1.5 & Hard \\
\hline Gymnothorax albimarginatus & 20.5 & 0 & Soft \\
\hline G. chilospilus & 4.3 & 46.2 & Hard \\
\hline G. cribroris & 0.3 & 0 & Hard \\
\hline G. dorsalis & 0.3 & 0.3 & \\
\hline G. eurostus & 0.5 & 6.4 & Hard \\
\hline G. fimbriatus & 0 & 4.8 & Hard \\
\hline G. formosus & 0 & 1.6 & \\
\hline G. fuscomaculatus & 0 & 0.9 & Hard \\
\hline G. margaritoforus & 0 & 5.6 & Hard \\
\hline G. moluccensis & 8.1 & 0.3 & \\
\hline G. nudivomer & 0.5 & 0 & Hard \\
\hline G. pindae & 0.3 & 5.7 & Hard \\
\hline G. pseudothyrsoideus & 0 & 1.1 & \\
\hline G. reevesi & 0.3 & 1.0 & \\
\hline G. reticularis & 3.2 & 0 & Soft \\
\hline G. richardsonii & 1.3 & 1.2 & Hard \\
\hline Gymnothorax sp.1 & 0 & 0.3 & \\
\hline Gymnothorax sp.2 & 1.3 & 0 & \\
\hline G. undulatus & 0 & 1.2 & Hard \\
\hline G. zonipectis & 0 & 1.3 & Hard \\
\hline Muraenichthys sp. & 10.5 & 0 & Soft \\
\hline Myrichtys maculosus & 1.1 & 0 & Soft \\
\hline Myrophis microchir & 8.1 & 0 & \\
\hline Plotosus lineatus & 2.7 & 0 & Hard/Soft \\
\hline Ptereleotris sp. & 8.1 & 0 & Hard/Soft \\
\hline Scuticaria okinawae & 0 & 0.4 & \\
\hline Scuticaria sp. & 0 & 0.4 & \\
\hline S. tigrina & 0 & 2.3 & Hard/Soft \\
\hline Strophidon sathete & 0.3 & 0.1 & Soft \\
\hline Uropterygius alboguttatus & 0 & 0.6 & Hard \\
\hline U. concolor & 1.1 & 1.8 & Hard/Soft \\
\hline U. fuscoguttatus & 0 & 0.6 & Hard \\
\hline U. macrocephalus & 0 & 0.4 & Hard \\
\hline U. polyspilus & 0 & 1.0 & Hard \\
\hline Uropterygius sp. 14b & 0.3 & 1.0 & \\
\hline U. supraforatus & 0 & 2.0 & Hard \\
\hline U. xanthopterus & 0 & 0.3 & Hard \\
\hline Unidentified fish & 0.5 & 0 & \\
\hline Unidentified Muraeninae 1 & 0 & 1.1 & \\
\hline Unidentified Muraeninae 2 & 0 & 1.1 & \\
\hline
\end{tabular}

caudata: Ineich et al. 2007). However, we have more details than in these previous studies: for example, our data show that the proportion of the prey item that is digested increases almost linearly with time, as expected from the symmetric cylindrical morphology of these items.

Relative to body size, Laticauda saintgironsi ate longer prey items than did L. laticaudata (means $34.39 \pm 0.43$ versus $31.95 \pm 0.44 \mathrm{~cm}$, respectively; ANCOVA with SVL as covariate, $F=$ 14.60, df $=1, \mathrm{p}<0.0001$ ). As expected, initial prey size (length) relative to snake size affected the rate of digestion (Spearman correlation, $\mathrm{p}<0.05$ ). Accordingly, digestion speeds differed between the 2 snake species (ANOVA, $F=5.06, \mathrm{df}=1, \mathrm{p}=0.03$; $20.6 \pm 0.08 \%$ of the prey being digested per day versus $16.2 \pm 0.04 \%$, respectively).

\section{Elapsed time between prey capture and arrival on land}

Both species displayed markedly bimodal distributions of the estimated duration of time between prey capture and return to the home island (Fig. 3). Approximately one-third of the prey items (26.7 and $33.6 \%$ for Laticauda laticaudata and L. saintgironsi, respectively; Yates $\chi^{2}=0.25, \mathrm{p}=0.71$ comparing the 2 species) were essentially undigested, with only a small portion of skin affected and no impact on prey length. Because sea kraits are relatively slow swimmers (Shine et al. 2003), these undigested items presumably were captured close to land $(\leq 0.5 \mathrm{~d}$, henceforth 'short foraging trips'). The remaining two-thirds of prey items were partially digested, sometimes to the point that only the head or the tail of the eel remained in the snake's stomach. These prey items were captured $>0.5 \mathrm{~d}$ before arrival on portion of eel length remaining undigested. The 37 snakes kept captive until completion of digestion provided overall mean values for digestive duration similar to previous records (8 d in Laticauda colubrina: Shetty \& Shine 2002; 6 d in L. saintgironsi and L. lati- land, and often over much longer periods (Fig. 3; henceforth, 'long foraging trips'). Looking only at these long trips, L. laticaudata tended to return to land more rapidly after feeding than did $L$. saintgironsi (ANOVA, $F=19.0, \mathrm{df}=1, \mathrm{p}<0.0001 ; 1.65 \pm 0.09$, max.: $3.05 \mathrm{~d}$ for 


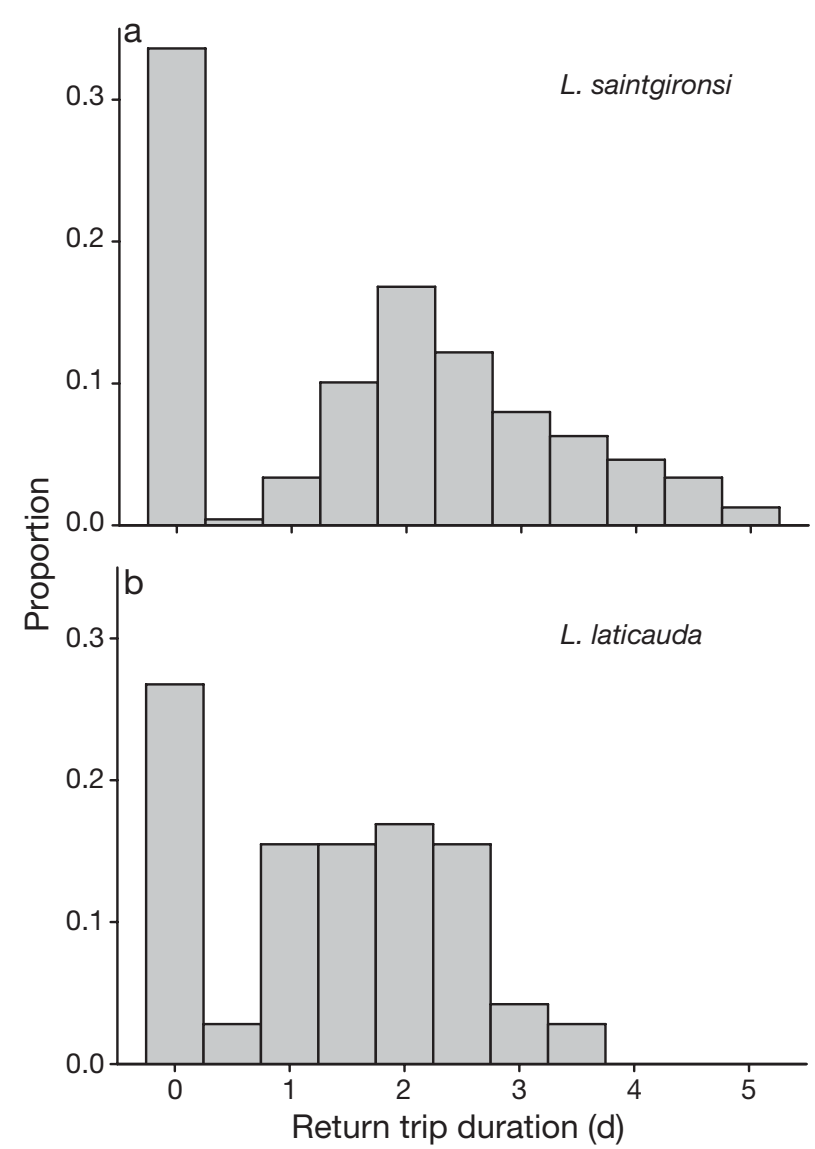

Fig. 3. Laticauda spp. Distribution of estimated return trip duration for the sea kraits (a) L. saintgironsi and (b) L. laticaudata. Estimated trip duration was calculated from 220 prey fragments for L. saintgironsi and 68 for L. laticaudata

L. laticaudata versus $2.29 \pm 0.08$, max.: $4.74 \mathrm{~d}$ for $L$. saintgironsi; Fig. 3). Initial prey length was negatively correlated with return trip duration in L. saintgironsi (i.e. snakes taking larger prey returned to land more rapidly; $F=12.64$, df $=1.15, \mathrm{p}<0.001$ ), but this effect was weak, explaining only $7 \%$ of the variance in elapsed times.

\section{DISCUSSION}

The method that we have developed to estimate the duration of foraging trips in sea kraits Laticauda spp. relies on a crucial assumption: that as soon as it captures a prey item, a sea krait returns to land. This assumption is supported by previous reports of snake behaviour (e.g. Saint Girons 1964, Guinea 1986) and by the marked impairment of a snake's swimming ability caused by a prey item in the stomach (Shine \& Shetty 2001). Sea kraits are vulnerable to predators such as sharks (Ineich \& Laboute 2002) and therefore apparently return to land as soon as they have fed. In keeping with this argument, $86 \%$ of the snakes that we captured coming ashore had a prey item in their stomach. Thus, the state of digestion of a prey item inside a snake returning to shore should provide a reliable indication, not only of the time that has elapsed since that prey item was consumed, but also of the duration of the snake's return trip from its foraging grounds to its home island.

The bimodal distribution of return-trip durations suggests that these snakes obtain about one-third of their prey from short foraging trips, close to their own home island, but that the rest of their food intake comes from a much wider area. The lack of intermediate durations (return trips 0.5 to $1 \mathrm{~d}$ long) suggests a clear geographic demarcation between these 2 sites. The similarity in trip durations between the 2 sea krait species is surprising, given the divergence in prey types between these taxa. Data on prey ecology suggest that Laticauda saintgironsi feeds mostly on eel species that live in crevices of hard-bottom habitats (coral, rubble, rock), whereas L. laticaudata tends to feed on species living in burrows on soft-bottom habitats (seagrass beds, mud flats, sand). Reef flats close to the home island provide both environments (S. Andréfouët unpubl. data), but if snakes move beyond these areas they presumably move longer distances to specific habitat types (isolated coral patches, reef flats, or the barrier reef for L. saintgironsi; vast soft-bottom areas of the lagoon for L. laticaudata).

Can we specify the geographic location of these foraging sites more precisely, by translating the duration of return trip into distances travelled by recently fed snakes? Both sea krait species exhibit similar speeds while swimming on the water surface (ca. $0.3 \mathrm{~m} \mathrm{~s}^{-1}$, authors' unpubl. data), but typical movements (even after feeding) consist of multiple dives that decrease their linear swimming speed (to about $0.1 \mathrm{~m} \mathrm{~s}^{-1}$; authors' pers. obs., unpubl. data). Focusing on Signal Islet, a typical islet of the lagoon, we calculate that sea kraits capture one-third of their prey very close to the islet, presumably on the reef flat (45\% hard bottom, $55 \%$ soft bottom: S. Andréfouët unpubl. data). The remaining prey items are taken from much further away, in a mean radius of $14 \mathrm{~km}$ (max. $23 \mathrm{~km}$ ) for Laticauda laticaudata and of $21 \mathrm{~km}$ (max. $38 \mathrm{~km}$ ) for L. saintgironsi (Fig. 4). Interestingly, the minimum estimated distance for 'long foraging trips' is $3 \mathrm{~km}$ for $L$. saintgironsi, corresponding to the closest reef flats situated south of Signal Islet (Fig. 4). For L. laticaudata, this minimum distance is smaller $(1 \mathrm{~km})$ and accords well with the widespread availability of soft-bottom areas in the lagoon.

These results significantly expand our view of the spatial scale over which sea kraits forage in the lagoon 
ecosystem (see Ineich et al. 2007). A single snake population can exploit a massive ocean area (at least $615 \mathrm{~km}^{2}$ surface area for Laticauda laticaudata and $1380 \mathrm{~km}^{2}$ for L. saintgironsi; perhaps up to $1660 \mathrm{~km}^{2}$ for L. laticaudata and $4500 \mathrm{~km}^{2}$ for L. saintgironsi). This result reinforces the position of sea kraits as top predators of the lagoon (Ineich et al. 2007): given that most islets in New Caledonia host snake populations, virtually the entire sea floor of the lagoon can be prospected by sea kraits (Fig. 4, see www.shom.fr/ for maps). Accordingly, in term of conservation, disturbances (pollution, over-fishing and coral reef destruction; Walker \& Ormond 1982, Linden 1999, Hughes et al. 2003, Riegl 2003) that influence local eel communities can reverberate over huge distances to influence predators based at islands many kilometres distant. Hence, the spatial scales of currently protected

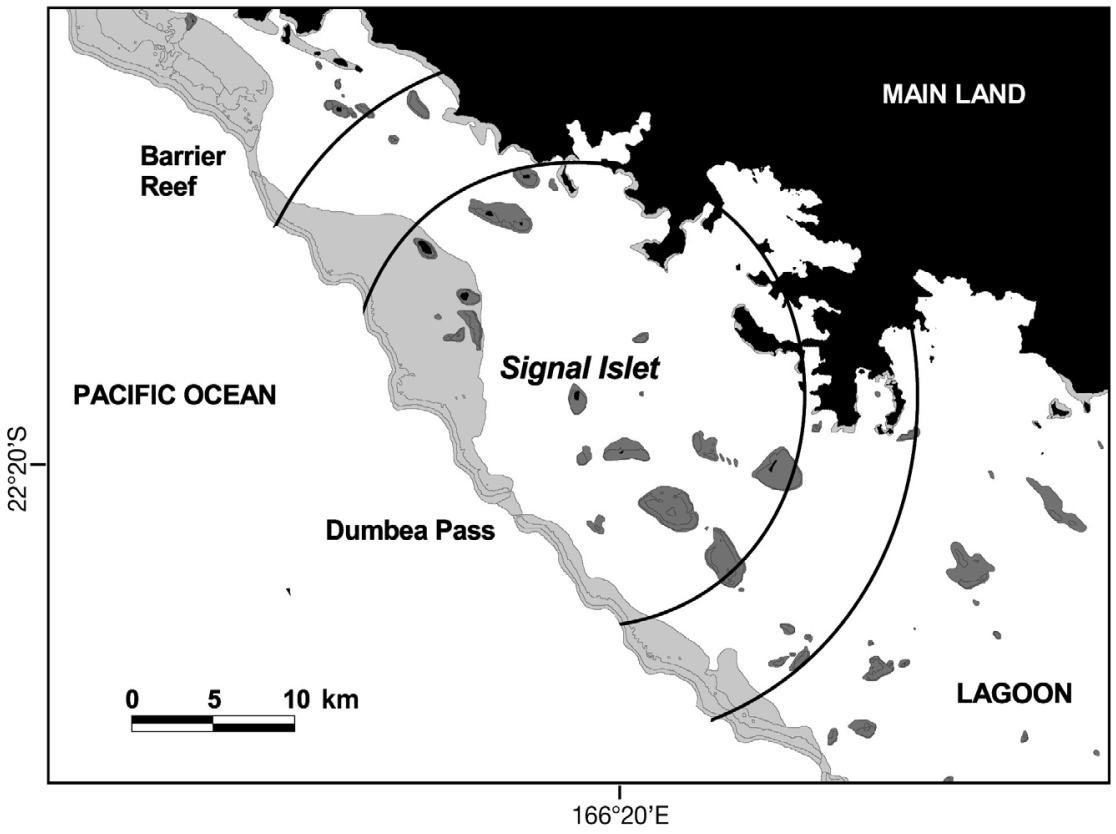

Fig. 4. Laticauda spp. Estimated mean foraging ranges of the sea krait population of Signal Islet (inner circle for L. laticaudata [mean radius of $14 \mathrm{~km}$ ]; outer circle for L. saintgironsi [mean radius of $21 \mathrm{~km}$ ]). Black areas indicate emergent land (mainland and islands); grey areas represent coral reef flats. The barrier reef and other fringing reefs are represented by light grey areas areas (usually a few $100 \mathrm{~km}^{2}$ ) need to be reconsidered. Conversely, disturbance to a home island (e.g. extermination of snakes due to resort construction; authors' pers. obs.) would greatly affect predation pressure on anguilliform fishes over a massive spatial scale.

Acknowledgements. R. Cambag helped to measure digested morays. B. Seret trained F.B. on moray identification. T. Cook made the map. S. Lorioux and M. De Crignis helped during fieldwork. We also thank F. Devinck, C. Goiran and D. Ponton (Aquarium de Nouméa, DRN Province Sud, IRD). We thank the CNRS, the University François Rabelais and the Australian Research Council for funding. The study was carried out under Permit Nos. 6024-179/DRN/ENV and 6024-3601/ DRN/ENV.

\section{LITERATURE CITED}

Böhlke EB, McCosker JE, Smith DG (1999) Muraenidae. In: Carpenter KE, Niem VH (eds) FAO species identification guide for fishery purposes. The living marine resources of the western Central Pacific, Vol 3. FAO, Rome, p 1643-1657

Brischoux F, Bonnet X (2007) Life history of sea kraits in New Caledonia. Mem Mus Nat Hist Nat (Fr) (in press)

Brischoux F, Bonnet X, De Crignis M (2007) A method to reconstruct anguilliform fishes from partially digested items. Mar Biol 151:1893-1897

Cherel Y, Duhamel G, Gasco N (2004) Cephalopod fauna of subantarctic islands: new information from predators. Mar Ecol Prog Ser 266:143-156

Cogger H, Heatwole H (2006) Laticauda frontalis (de Vis, 1905) and Laticauda saintgironsi n. sp. from Vanuatu and New Caledonia (Serpentes: Elapidae: Laticaudinae) - A new lineage of sea kraits? Rec Aust Mus 58: $245-256$

Colwell RK (2005) EstimateS: statistical estimation of species richness and shared species from samples, Ver. 7.5. Available at http://viceroy.eeb.uconn.edu/EstimateS

Elliott PF (1988) Foraging behavior of a central-place forager: field tests of theoretical predictions. Am Nat 131(2): 159-174

Froese R, Pauly D (eds) (2006) FishBase, Ver. 12/2006. Available at www.fishbase.org

Guinea ML (1986) Aspects of the biology of the common Fijian sea snake Laticauda colubrina (Schneider). MSc thesis, University of the South Pacific, Suva, Fiji

Guinet C, Dubroca L, Lea MA, Goldworthy S, Cherel Y, Duhamel G, Bonadonna F, Donnay JP (2001) Spatial distribution of foraging in female Antarctic fur seals Arctocephalus gazella in relation to oceanographic variables: a scale-dependent approach using geographic information systems. Mar Ecol Prog Ser 219:251-264

Heatwole H (1999) Sea snakes. Australian Natural History Series. University of New South Wales, Sydney

Hindell MA, Bradshaw CJA, Harcourt RG, Guinet C (2003) Ecosystem monitoring: Are seals a potential tool for monitoring change in marine systems? In: Gales NJ, Hindell MA, Kirkwood R (eds) Marine mammals. Fisheries, tourism and management issues. CSIRO Publishing, Melbourne, p 330-343

Hughes TP, Baird AH, Bellwood DR, Card M and 13 others (2003) Climate change, human impacts, and the resilience of coral reefs. Science 301:929-933

Ineich I, Laboute P (2002) Sea snakes of New Caledonia. IRD 
et Muséum National d'Histoire Naturelle Editions, Collection Faune et flore tropicales, Paris

Ineich I, Bonnet X, Brischoux F, Kulbicki M, Seret B, Shine R (2007) Anguilliform fishes and sea kraits: neglected predators in coral reef ecosystems. Mar Biol 151:793-802

Linden O (1999) Coral mortality in the tropics: massive causes and effects. Ambio 27:588

Magurran AE (1988) Ecological diversity and its measurement. Croom Helm, London

Magurran AE (2004) Measuring biological diversity. Blackwell Publishing, Oxford

Naulleau G (1983) The effects of temperature on digestion in Vipera aspis. J Herpetol 17(2):166-170

Riegl B (2003) Climate change and coral reefs: different effects in two high-latitude areas (Arabian Gulf, South Africa). Coral Reefs 22:433-446

Saint Girons H (1964) Notes sur l'écologie et la structure des populations des Laticaudinae (Serpentes: Hydrophiidae) en Nouvelle-Calédonie. Rev Ecol Terre Vie 111: 185-214

Shetty S, Shine R (2002) Activity patterns of yellow-lipped sea kraits (Laticauda Colubrina) on a Fijian island. Copeia 2002:77-85

Shine R, Shetty S (2001) Moving in two worlds: aquatic and

Editorial responsibility: Otto Kinne (Editor-in-Chief),

Oldendorf/Luhe, Germany terrestrial locomotion in sea snakes (Laticauda colubrina, Laticaudidae). J Evol Biol 14:338-346

Shine R, Sun L (2003) Attack strategy of an ambush predator: Which attributes of the prey trigger a pit-viper's strike? Funct Ecol 17:340-348

Shine R, Cogger HG, Reed RN, Shetty S, Bonnet X (2003) Aquatic and terrestrial locomotor speeds of amphibious sea-snakes (Serpentes, Laticaudidae). J Zool 259:261-268

Smith DG (1999a) Myrocongridae: thin morays. In: Carpenter $\mathrm{KE}$, Niem VH (eds) FAO species identification guide for fishery purposes. The living marine resources of the western Central Pacific, Vol 3. FAO, Rome, p 1641-1642

Smith DG (1999b) Congridae: conger eels. In: Carpenter KE Niem VH (eds) FAO species identification guide for fishery purposes. The living marine resources of the western Central Pacific, Vol 3. FAO, Rome, p 1680-1688

Smith DG, McCosker JE (1999) Ophichthidae: snake eels, worm eels. In: Carpenter KE, Niem VH (eds) FAO species identification guide for fishery purposes. The living marine resources of the western Central Pacific, Vol 3. FAO, Rome, p 1662-1669

Walker DI, Ormond RFG (1982) Coral death from sewage and phosphate pollution at Aqaba, Red Sea. Mar Pollut Bull 13: $21-25$

Submitted: February 28, 2007; Accepted: June 25, 2007

Proofs received from author(s): November 9, 2007 